Chapter 12

\title{
WAVE EFFECT ON THE COAST FORMATION AND EROSION
}

\author{
Walenty Jarocki \\ Professor, Construction Engineering \\ Institute, Warsaw
}

KINDS OF SEDIMENT̀ MOVED BY WAVES

Sediment may be moved in consequence of the action of wind wares and of water currents. These two lactors may act separately or together.

Bediment may be divided into 3 types:

suspended load, bed load and detritus load. Depending on kind of movement of particles a bed load may be: rolled, slip, sprung and swollened.

In the near-shore or in the open zone for waves the bed load and detritus load moves mostly in consequence of the action of wind waves. In open zones for waves where the tidal flow and tidal fall are appearing, the bed and detritus load are moving inconsequence of the action of the wind waves and. of water currents.

The wind waves usually are small and the velocity of water currents may be larger in the narrow and long straits. Therefore the water current is in these zones the principal factor which moves the suspended, bed and detritus loads.

The wind waves and water currents move the suspended, bed and detritus loads in the shallow external zones of the water area especially if the bottom is argillaceous.

\section{VARIOUS DEPTH EFFECT ON THE SEDIMENT MOVEMENT}

The wares may cause the sediment movement on the depth equal about 0,4 of the greatest possible length of wave. Intensity of waves action decreases when the depth of sea decreases. Therefore in the shallow parts of sea the waves cause a larger scoure of bottom and they raise a great quantity of sediment. If the sea has a great depth then the scoure of the bottom and the raising of sediment may be caused only by means of heary wares.

The waves are moving a suspended load towards the wave propagation and in the opposite direction. Thus the suspended load are moving from a shallow parts of the sea to a deep parts in which the transport of suspended material is smaller. In these deep parts a suspended load may fall on the bottom. Thus the bottom erosion takes place in shallow parts of sea and the accumulation of sediment in deep parts. 


\section{INVESTIGATION OF THE ACTION OF WAVES ON THE SEDIMENT MOVEMENT.}

Various authors explain differently the mechanism of action of waves on the sediment movement. Some authors consider that the waves are rajsing the soil fractions from the bottom and water currents transfer them along the seaboard. The other authors suppose that each wave shears some soil in the bottom in littoral zone of the waves and wind is oblique to the shoreline. Beach currents catch and transport the sediment particles along the seaboard.

These authors suppose when the wind is in the direction of seaboard /from sea/ then the bottom currents move in the opposite direction. These currents transport the ground particles in the direction of sea and thus the seaboard erosion arises. When the wind direction is opposite, the botto currents axise in the direction of seaboard and they cause the transportation of ground and the accumulation of seaboards These reasons show that the action of waves would cause only the separation of ground particles and their ascending.

Oux last investigations and observations of the sediment movement have led the conclusion that the waves may cause the raise of the sediment partciles and also their tran port . The charactex of this transport depends on the wave kind and on the height and length of waves.

General quantity of the lifted particles by means of waves increases as the power of waves or height and length of waves increases. If the power of waves decreases these particles fall.

The waves are able to transport the bed load and detritus load without cooperation of the water current in spite of horizontal or inclined bottom. Under the action of waves the sediment moves the oscillatory movement.

The waves move the bed load in the shallow exterior zones with the horizontal bottom only, towards the wave propagation. This material may be moved perpendicular the slope, according to the wave direction ox in the opposite on If the approaching wave creates the acute angle to the shoreline then the bed load moves near the seaboaxd. The transport of the bed load and of detritus loa change if the water current and waves appear simultaneously. The water cuxrent acts generally on the detritus load becaus the water moves this material easier than the bed load which roils on the bottom. 


\section{WAVE EFFEC'T ON THE COAST FORMATION AND EROSION}

\section{COAST FORMATION AND EROSION}

The action of waves causes the movement of suspended load from zones with a great quantity of this material to zones with a smaller one.

The observations are showing that the bottom and the board slope of the shallow open zones consists usually of the coarse-grained particles because their raising is difficult. This phenomenon may be explained this way, the all light clayey close-grained particles were lifted up firstly and than they fell in deep zones.

The movement of waves is the main factor which causes the formation of the coast and bottom in littoral zones. The action of waves may cause the erosion of seaboard or may cause the accumulation of coast. The investigations showed that the short waves cause the erosion of seaboard and the long ones - the accumulations /fig. 1,2,3/. The process of action of waves be divided into 3 stages. In the first stage, when the wave reaches the critical depth, the wave crest comes down, pierces the water mass and attaines the slope surface. The orbital velocities of the superficial particles of water are always larger then the near-bottom velocities. Therefore the superficial particles of water carry along the ground particles from the slope to the limit of the critical depth because they keep the rotary motion.

Thus the cylindrical hollow arises on the slope in this place, where the water strikes. The ground particles move down of the slope and underwater rampart raises about hollow.

In second stage the wave strikes against a water surface and it causes the two new waves which strike against a slope. The strokes of these waves are weaker than the strokes of the main first wave. In that way these two new waves produce two hollows and two ramparts on the slope. The size of these hollows and ramparts decreases as they approach to the water surface.

In the third stage the oscillatory motion of water particles turns into translatory motion and it cause the uprush.

At first the velocity of movement of the rampart and hollow down is considerable, later this velocity quick decreases and the rampart and hollow become stable.

The lencth of way from the place of the formation of underwater rampart to the lasting position may be taken

$$
I_{1}=5 / 2 \mathrm{~h} /
$$


The water depth above rampart in the stage of stabilization

$$
\mathrm{H}_{1}=0,75 / 2 \mathrm{~h} /
$$

The depth above hollow

$$
\mathrm{H}_{2}=1,6 / 2 \mathrm{~h} /
$$

The depth above hollow is proportional to $2 \mathrm{~h}$ and inversely proportional to $D$ and $i$

$$
\mathrm{H}_{2}=\mathrm{f} / \frac{2 \mathrm{~h}}{\mathrm{Di}} /
$$

The distance between the top of the rampart and the centre of hollow

$$
1_{2}=3 / 2 \mathrm{~h} /
$$

The average width of the erosion on the slope

$$
\begin{aligned}
& I_{3}=6 / 2 \mathrm{~h} / \\
& \text { where : } 2 \mathrm{~h}-\text { length of wave } \\
& \mathrm{D}-\text { dimension the sediment partioles } \\
& 1 \text { - wave steepness. }
\end{aligned}
$$

The process of the action of the long waves is other than the action of short ones. The intensity of the subsidence of wave crest is smaller and the second new wave do not formed. The larger quantity of water goes up slope and this water turns into the uprush.

When the slope consists of impervious ground then almost a.l water rolls up on the slope. This water carries a ground particles which were raised first from water zones where was the critical depth. When this water meets the main beachoomber then the velocity this water decreases. At that time the ground particles fall and create a rampart of the sediment on the slope.

When the slope consists of coarse-grained soil then the considerable quantity of water penetrates in the slope and the ground particles stay on the slope near the water level. This quantity of water, which rolls on slope, is not taken of the sediment.

Therefore the long waves forme the supermarine rampart independently of inclination of slope, if it consists of coarse-grained soil.

It is the opinion that the material for formation of rampart is forthcominged from sea. The investigations showed 
WAVE EFFECT ON THE COAST FORMATION AND EROSION

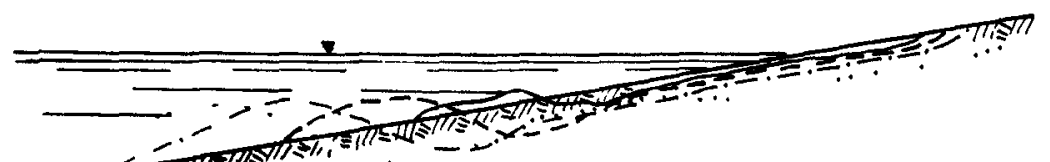

ग्रुसा

\section{Fig 1}

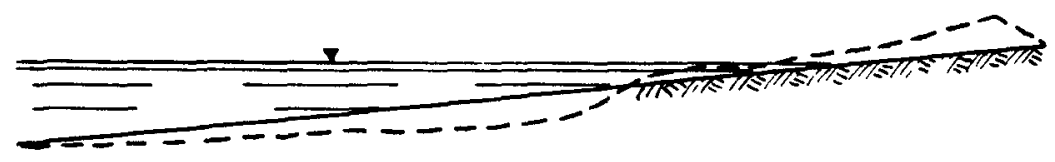

Fig 2

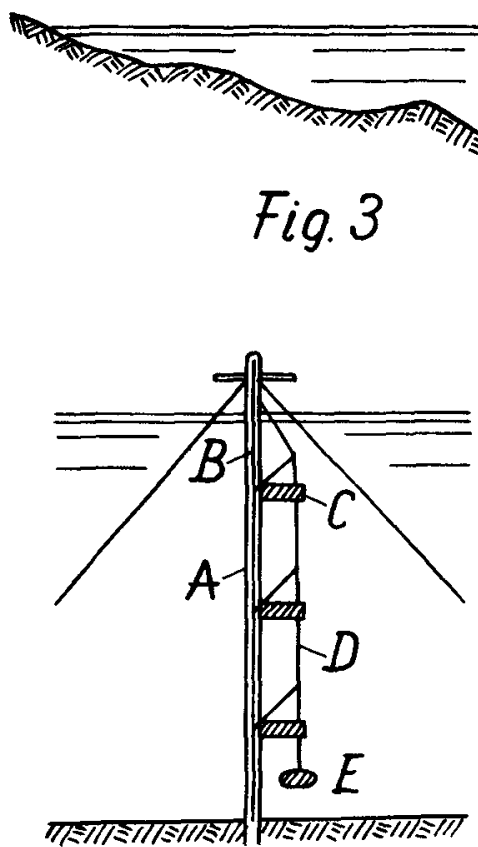

Fig. 4

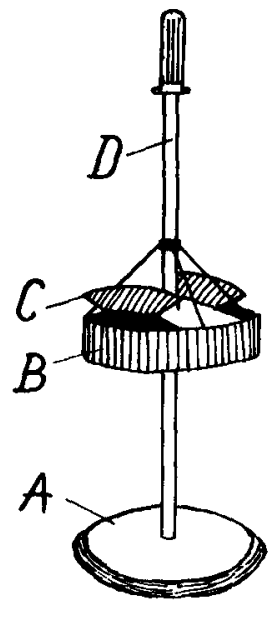

Fig. 5

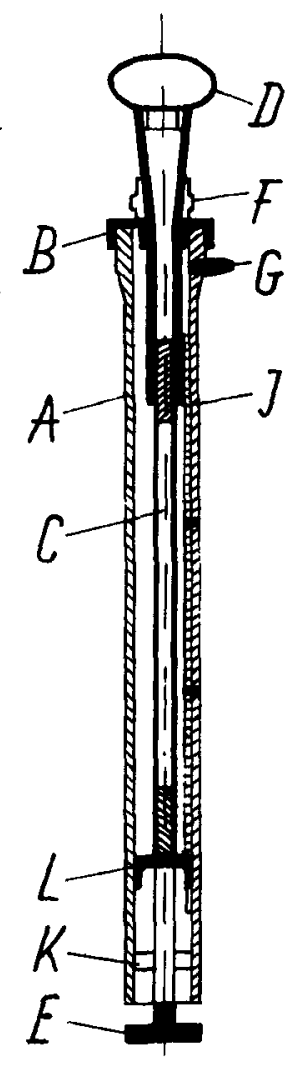

Fig. 6

Fig. 1. Action of short waves on the coast formation Fig. 2. Action of long waves on the coast formation

Fig. 3. Cross - section of the coast after action of short waves

Fig. 4. Samoilow's device

Fig. 5. Bottom bathometer of Bozich-Guriew

Fig. 6. Water sound of Bozich 
that this opinion is wrong.

At first the intensity of the board reforming is large and afterwards it decreases. The intensity depends on the board height.

\section{INSTRUMENTS OF SEDIMENT MEASUREMENT}

The transport of near-shore sediment was investigated by Samoilow's device, by bottom bathometer of Bozich-Guriew and by testing ditches and walls.

Samoilows device / fig. 4 / consists of following main parts: a/ a metallic tube A with longitudinal crenel, b/ a chain $B$ which links are moved along the tube, $c /$ a set of metallic disches $C$ with caps, fastened to the chain, d/ a wire rope $D$ with the upper end over water-level and the lower one in water together with charge $E$. The disches may be opened, shuted or may be Iifted along the tube.

The device plunges into water when there are no waves. The dishes are suspended along the submarine part of the tube. These dishes are filled with non-cohesive soil and they are opened in water. Systematic observations are made in time of the action of waves. When the waves are calmed down then the dishes shut and partiy taken from water. The aim of this procedure is to state from which of these dishes the sand is removed. When the lower dish without ground will be taken out then the depth of plunge of this dish should be noted.

These measurements are performed with sand of various fractions. Thus the action of waves of various intensity on the movement of different particles of sediment is determined. By these measurements also the depth of the wave action of various intensity may be defined.

The bottom bathometer of Bozich-Guriew / fig.5/ consists of following main parts: a/ round metallic bedplate $A$ with sharp borders; the thin layer of sand is pasted to the upper surface of the bedplate, b/ cylinarical cap $B$, which is fastened to the short tube with valves $C, c /$ compass which may be moved along the rod but may not be turned around, d/ the raising cap velocity regulator, e/ vertical metallic tube D, which is screwed up under bedplate of bathometer which serves to take the ground samples.

The construction this bathometer enables to load the bed sediment from all sides of the bathometer bedplate. This is important, because the diredtion of the sedinent movement may be different as the direction of waves. This bathometer serves to determine:

a/ the quantity of transported sediment in a time unit,

$\mathrm{b} /$ main direction of the sediment movement,

c/ average velocity of the sediment movement,

di' average thickness of the sediment layer. 
The approximate measurements of sediment were performed in various places in bottom by testing ditches. The filling of these ditches depends on intensity of sediment movement.

Approximate quantities of sediment were determined also by means of testing walls, which were built perpendi-cularly to the principal direction of the sediment movement.

The measured profiles serve to compare the sediment trans port in time of the action of waves of various intensity direction etc.

\section{INSTRUMENTS OF SEDTMENT MEASUREMENT IN THE IABORATORY.}

The various instruments were used in laboratory to the investigation of dynamics of suspended and ditritus sediment, to the observation of dynamics of separate particles of bed and detritus load, and to the examination of movement of near-bottom sediment.

Fixation of the dynamics of suspended and detritus load was performed by means of water sound of Bozich. This device enables the sampling of water with suspended and detritus particles in every time and in every place.

The quick sampling is necessary because the velocity of water fluctuation is large and the role of various phases of the wave action /e.g. crest and hollow/ must be fixed.

The time of sampling of water hesitates from 0,015 to $0,20 \mathrm{sec}$ including the time of opening and of closing of sound. The device gives the possibility also of sampling of detritus load without the artificial raising of smail particles which are on bottom.

The water sound /fig.6/ consists of following main parts: a/ cylindrical dish $A$ with hermetic cap $B$, b/ vertical rod $C$ with arm $D$ above, and with buckler $E$ below, c/ arrangement $F$ to regulation of height opening of buckler, d/ tripod, e/ little pumping unit.

The cylindrical dish $A$ has inside a guide rod $I$ and guide ring $K$. The end of vertical rod $C$ has the treading on which may move a piston I. This piston is connected with guide $\operatorname{rod} I$, the piston $I$ moves along the dish $A$ if the rod $C$ is turned.

The buckler E is fastened stationary to the rod C. This buckler is immovable, when the rod $\mathrm{C}$ is turned, but the piston $I$ moves if the rod $C$ is moved along the dish $A$. The sampling of this sound consists of the following operations:

a) putting of piston $I$, by revolution of arm $D$, in this position which allows to take the water samples of the necessary capacity,

b/ putting of regulator $F$ in this position which insures the necessary opening device,

c/ closing of dish A from below by means of buckler $E$, 
d/ decrease of air pressure 0,3-0,5 atmosphere,

e/ closing of tap $G$,

1/ putting of lower end of water sound in place of sampling,

$\mathrm{g} /$ quick opening of device by means of arm $D$.

The water penetrates from below to the dish $A$, because the air pressure there small.

The dymamics of the separate particles of sediment was investigated by means of conventional large particles of soil and by means of floaters. As conventional particles were used: aniline drops, pea stones, small balls of plaster etc.

Intensity of the transference of bed load was examined by means of the survey of bottom profiles befor and after the investigation

REFERENCES

Bozich P.K./1948/. Wave observations and investigations. Cebertowich $R$. $/ 1958 /$. Model investigations of water buildings. Warsaw.

Gugniaiew J. E./1955/. Laboratory investigations of dinamics of sand slope formation. Moscow

Jarocki W. /1957/ Sediment movement in rivers. Gdynia. 